\title{
A Different Light in Predicting Ungauged Basins: Regionalization Approach Based on Eastern USA Catchments
}

\author{
Syed Abu Shoaib ${ }^{1}$, András Bárdossy ${ }^{2}$, Thorsten Wagener ${ }^{3}$, Yingchun Huang ${ }^{2}$ and Nahid Sultana ${ }^{4}$ \\ 1. Department of Environmental Science, Independent University, Bangladesh (IUB), Dhaka 1229, Bangladesh \\ 2. Institute for Modelling Hydraulic and Environmental Systems, University of Stuttgart, Stuttgart D-70569, Germany \\ 3. Department of Civil and Environmental Engineering, Pennsylvania State University, Pennsylvania 16802, USA \\ 4. Institute of Environmental Studies, University of New South Wales, Sydney NSW 2052, Australia
}

\begin{abstract}
This paper reviewed the existing methods in regionalization studies to predict ungauged catchments and considering all the aspects a different methodology is developed, which is named as RDS method. ROPE (robust parameter estimation)-D (data depth)-S (spatial proximity) together gets this name RDS. Catchment properties and hydrological model parameters are used consistently to predict ungauged basin. This study explores the potential of the regionalization process to predict ungauged basins using the data of the Eastern USA catchments. Two conceptual rainfall-runoff hydrological models: HYMOD and HBV are used in this study. Analysis shows 95\% success in predicting ungauged basins with HBV and 90\% success with HYMOD. It is undoubtedly perceptible that RDS method is very effective in predicting ungauged basin and regionalization is independent of the conceptual rainfall-runoff model.
\end{abstract}

Key words: Ungauged basin, rainfall-runoff modeling, regionalization, robust parameter.

\section{Introduction}

The prediction of the hydrologic response of ungauged catchments is a deep-seated problem in hydrology. Regionalization is one of the ways where a conceptual model is applied to a representative number of gauged catchments and statistical relationships are derived between model parameters and catchment characteristics to predict ungauged basins. This has so far been done with only limited success, particularly for continuous simulation models $[1,2]$. Predictions with these models are often deterministic, focusing on the most probable forecast, without an explicit estimate of the associated uncertainty. However, uncertainty arises from incomplete process representation, uncertainty in initial conditions, input, output and

Corresponding author: Syed Abu Shoaib, senior lecturer, research fields: water, environment and climate. E-mail: shoaibmila@yahoo.com. parameter error [3]. In addition, Errors of $100 \%$ in the simulation of high flows or low flows are not unusual. Still, uncertain information is more useful than incorrect certainty. Even if the authors do not know the exact outcome, knowledge of its probability can be very valuable [4]. From the uncertain prediction, the best turnover has to be found to reach the authors' goal.

Regionalization techniques provide a mechanism to determine the hydrologic behaviors of gauged watersheds. The classification of gauged watersheds into regions according to the stream flow or watershed and climatic variables, provides a way to extend information from gauged watersheds to ungauged ones. Though it is a challenging process, still now, hydrologist developed several regionalization methods to predict ungauged basins [5-8]. Generally this study can be classified in six groups: (1) spatial proximity; (2) the multi-model approach; (3) data depth; (4) flow duration curve; (5) regression; (6) physical similarity. 
Based on temporal dimension, regionalization methods can be broadly classified into two groups: The first group works with the estimation of continuous time series of stream flows [9, 10]; the other group estimates selected hydrological indices, such as base flow index and the mean annual flow $[11,12]$, or various percentiles of the flow instead of continuous time series (e.g., regionalization of the FDC-flow duration curve) $[13,14]$. Further classification can be done within each group. The methods used for estimating the time series of stream flows can be further sort out into four sub-groups: (1) transfer of model parameters, whereby a catchment similarity analysis is conducted $[5,15]$ and parameters of gauged catchment are used in simulations for similar ungauged or poorly gauged catchment [7, 16]; (2) model parameter estimation by developing regression relationships between model parameters and catchment characteristics [14, 15]; (3) use of data depth [17]; (4) other regionalization techniques such as spatial interpolation of parameters [10] or regional pooling of data for parameter estimation for ungauged catchments [18]. Castellarin et al. [13] classified regionalization methods for FDC into statistical, parametric and graphical approaches. Masih et al. [14] examined the FDC similarity criterion to predict ungauged catchments. In spite of substantial advancement in hydrology, the prediction of stream flow for ungauged or poorly gauged catchments still remains as most important challenge $[2,6,19]$. In this regard, data transfer from a gauged "donor" basin to ungauged basin are seen as superior to the estimation from catchment descriptors alone. A donor or analogue basin (e.g., close to subject catchment, of similar size, physiography, land use, soil, etc.) must offer gauged data of good quality [11]. In this study, the authors identify the gauged donor catchments to predict in assumed ungauged basins.

The aim of this paper is to show the new dimension in predicting ungauged basins by combining parameters of a conceptual rainfall-runoff model with catchment properties specifically, the paper deals with several questions: (1) Are catchment properties weights perfectly correlate with the parameter of the conceptual rainfall-runoff model to predict ungauged basins? What is the appropriate way of combining the both? (2) How the Regionalization differ in two different conceptual rainfall-runoff model? (3) Are model parameters sensitive enough with changing catchment properties? What is the effect of selecting good and bad donor catchments considering model efficiency?

Calibration of two conceptual rainfall-runoff model-HYMOD and HBV has been done from 279 Eastern USA catchments using runoff data between 1948 and 2003 during which the climatic variables have substantially changed. The dependency between the model parameter and catchment properties has been checked which ultimately enhance the understanding of the physical process of the hydrological system. Later on the boundary, catchments (donor) examined to regionalize with inside catchments (ungauged catchments).

\section{Data and Study Domain}

\subsection{Study Domain and Data Set}

This study was undertaken by using data of the Eastern USA catchments from the period 1948 to 2003. The Eastern United States has a diversified topography including rolling hills and temperate forests, which is one of the important features of the area. A line of low mountains of the Appalachian Mountains separates the eastern seaboard from the Great Lakes and the Mississippi Basin. The five Great Lakes are located in the north-central portion of the country. The Southeast United States contains subtropical forests and, near the gulf coast, mangrove wetlands, especially in Florida. West of the Appalachians lies the Mississippi River basin and two large eastern tributaries, the Ohio River and the Tennessee River. The Ohio and Tennessee Valleys and the Midwest consist largely of rolling hills and productive farmland, stretching south to the Gulf 
Coast (Fig. 1). Elevation ranges from $21.9 \mathrm{~m}$ to 1,212 $\mathrm{m}$ above sea level. 279 catchments data were used with areas ranging from $67.34 \mathrm{~km}^{2}$ to $10,095.87 \mathrm{~km}^{2}$ and a median area of $1,993.005 \mathrm{~km}^{2}$.

\subsection{Catchment Classification}

The Eastern USA catchments were classified by long term potential evapo-transpiration and precipitation data used in the Budyko curves [20]. According to Budyko, catchments with a ratio (PE/P) larger than unity are termed water limited or arid, while catchments with a ratio smaller than unity are termed energy limited or humid. Based on this classification most of the catchments in Eastern USA are energy limited (Fig. 2).

To assist in the interpretations and make it transferable to other climatic regions, the analyses are given for the entire set of catchments and for two subclasses with a ratio of potential evapo transpiration and precipitation larger than 1.0 (termed "drier" catchments) and a ratio less than 0.6 (termed "wetter" catchments). Out of the 279 catchments, 75 are classified as wetter catchments, and 14 classified as drier catchments. The remaining 190 catchments are considered as medium type catchments. The drier catchments are mainly located in the western regions in the eastern USA, while the wetter catchments are mainly located in the south east part of the eastern USA (Fig. 1). The thresholds of 0.6 and 1.0 were chosen as a compromise between balancing the number of catchments in the groups and making the in between 0.6 and 1.0 groups clearly different with respect to the Budyko curve.

\subsection{Climate Gradient and Trend of Change}

Annual mean values of catchment precipitation $P$, air temperature, potential evapo transpiration, specific runoff $Q$ (i.e., runoff divided by catchment area), the ratio of runoff and catchment precipitation $Q / P$, and the fraction of catchment area covered by snow were

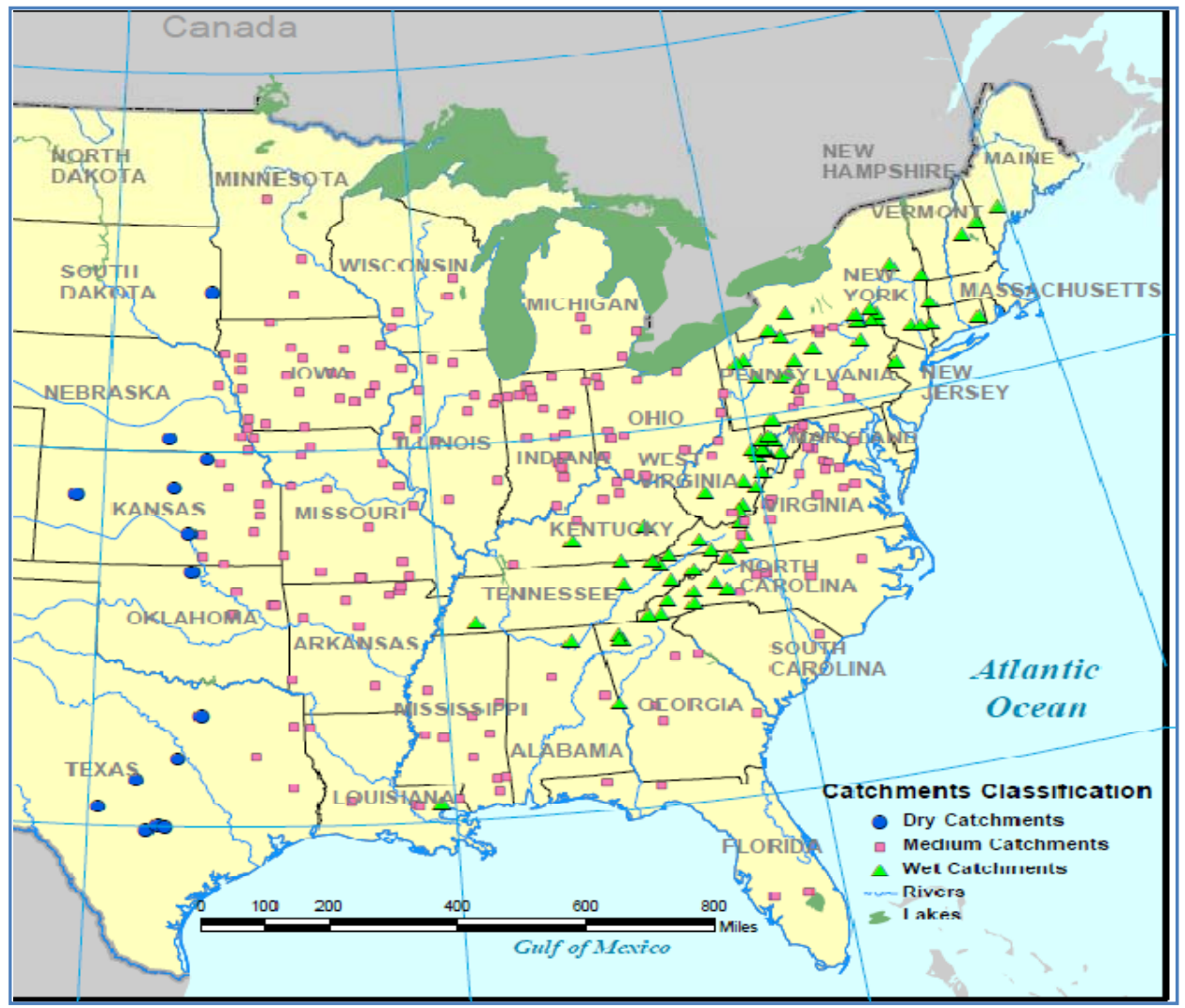

Fig. 1 Location of the catchment outlets and classification into drier catchments (circle), wetter catchments (triangle) and medium catchments (square) depending on the ratio of potential evapo-transpiration and precipitation. 

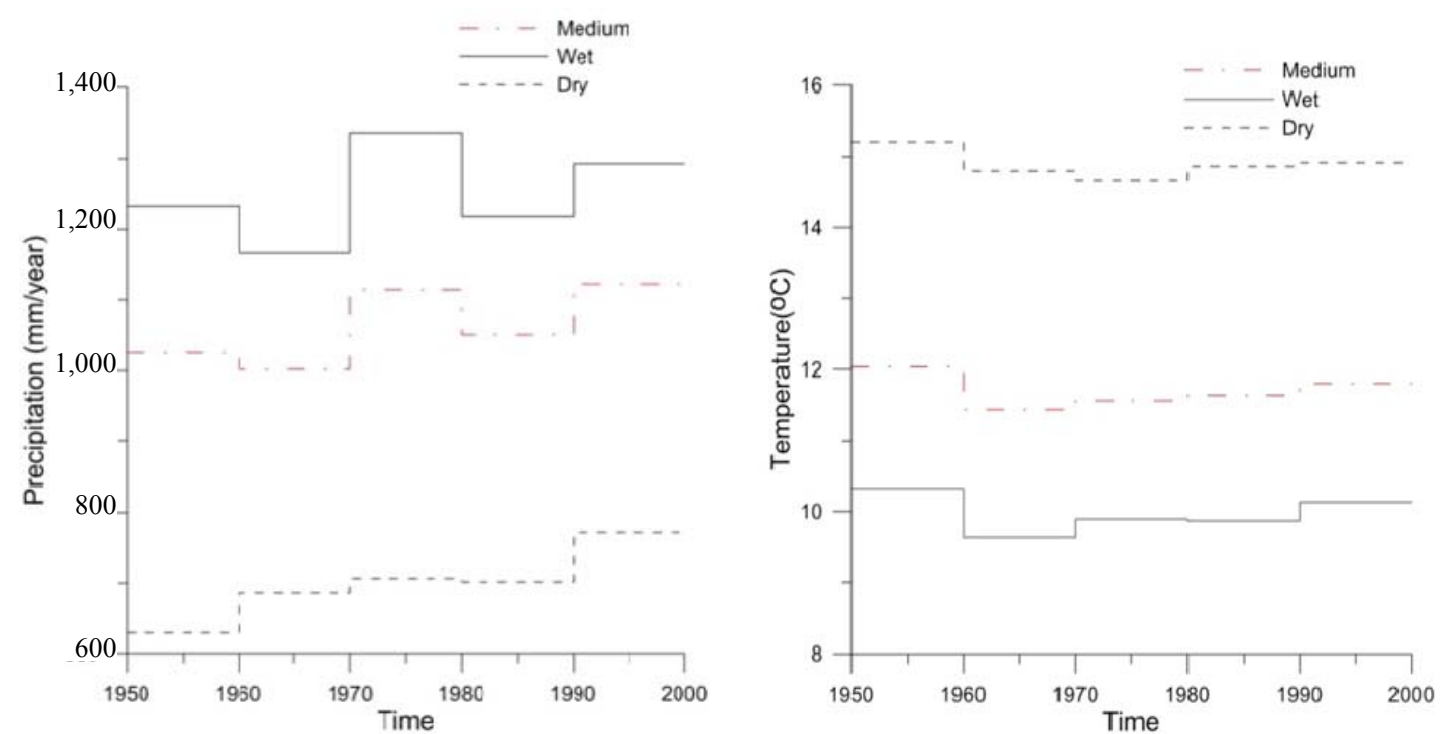

Fig. 2 Ten years mean annual values of climatic variables precipitation and temperature averaged over the 279 Eastern USA medium catchments (red dot and solid lines), averaged over the wetter catchments (solid grey lines) and averaged over the drier catchments (dashed grey lines).

analyzed for the period 1948 to 2003 . The black lines are the averages over the 279 catchments and the grey solid and grey dashed lines are the averages over the wetter catchments and the drier catchments, respectively. The average annual precipitation over all Eastern USA catchments varies from $465.9 \mathrm{~mm} / \mathrm{yr}$ to $2,072 \mathrm{~mm} / \mathrm{yr}$ and has slightly increased over the last three decades. There are large differences between the drier and wetter catchments, but the spatial average tends to increase for all catchment groups. For the drier catchments, the spatial average has increased from $465.9 \mathrm{~mm} / \mathrm{yr}$ to 2,072 $\mathrm{mm} / \mathrm{yr}$, while for the wetter catchments, the spatial average has increased from 973.6 to $2,072 \mathrm{~mm} / \mathrm{yr}$. The air temperature trends are even more pronounced. Between 1948 and 2003, mean annual air temperatures have variation by almost $2{ }^{\circ} \mathrm{C}$, on average, for all the catchments. The change is slightly larger for the wetter catchments and smaller for the drier catchments. Potential evapo-transpiration (estimated from air temperature) has increased from about $513.5 \mathrm{~mm} / \mathrm{yr}$ to $1,160.7 \mathrm{~mm} / \mathrm{yr}$ within the period 1948 to 2003 (averages over all Eastern USA catchments).

It is clearly visible from Figs. 2 and 3, an increase in runoff due to increase in precipitation over the last decades. However, no temporal trend in the mean annual runoff $Q$ is apparent in Fig. 3. This applies to the average of all catchments as well as the wetter and drier sub-regions. The increase in precipitation over the last decades seems to have been compensated by an increase in evapo-transpiration, so runoff remained rather constant. The average runoff of the drier catchments is only about one-third of that in the wetter catchments, but the time patterns are similar. Low flows ( $Q 95$ - the discharge exceeded $95 \%$ of the time) and high-flow quantiles ( $Q 5$ - the discharge exceeded $5 \%$ of the time) do not show time trends either. Because of the trend in precipitation and lack of trend in runoff, the ratio of $Q / P$ shows a similar trend (Fig. 3).The average fraction of the catchment area covered by snow is much lower in the drier catchments than in the wetter catchments as the former are located in the lowlands while the latter are in highlands.

\section{Methodology}

\subsection{Methodology-RDS Method}

In predicting ungauged basins, a different approach has been introduced referred as the RDS. The RDS method is found to be an effective method because the used variables are representative of the whole catchments status (Fig. 4). R (ROPE)-D (data depth)-S 

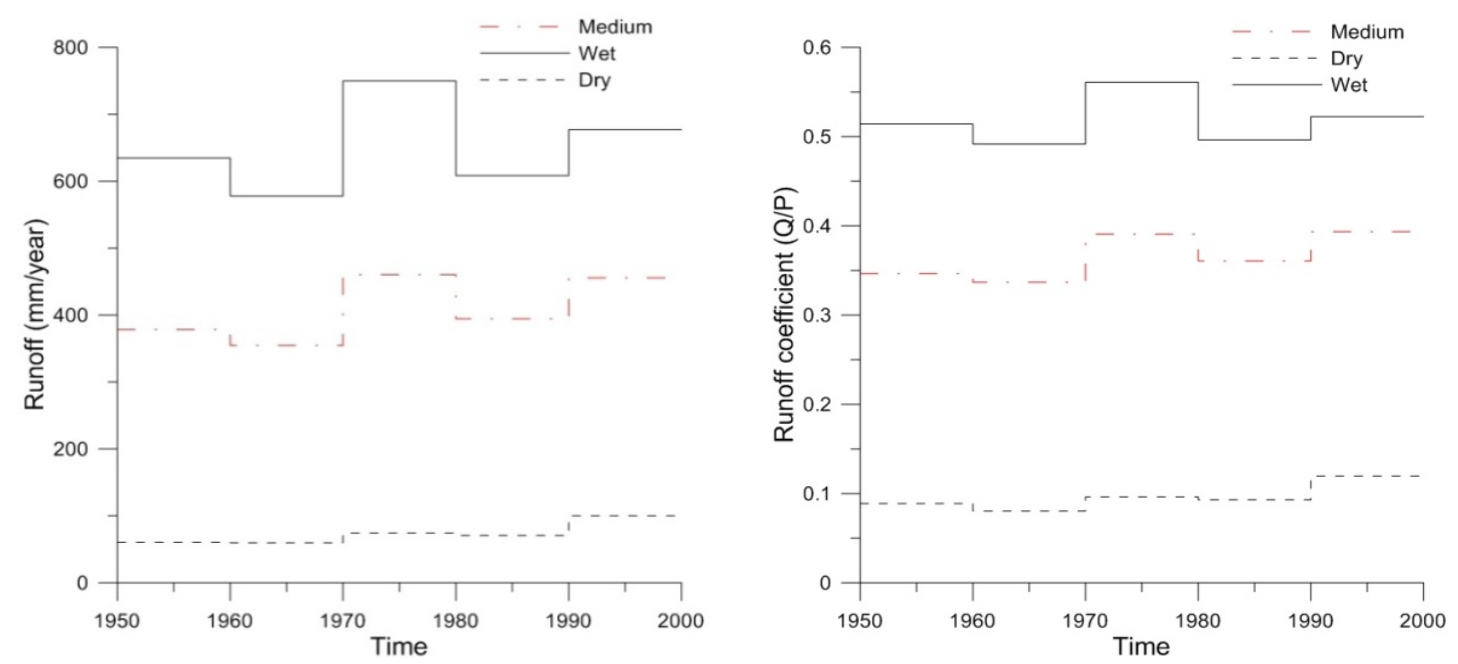

Fig. 3 Ten years mean annual values of climatic variables runoff and runoff coefficient averaged over the 279 Eastern USA medium catchments (red dot and solid lines), averaged over the wetter catchments (solid grey lines) and averaged over the drier catchments (dashed grey lines).

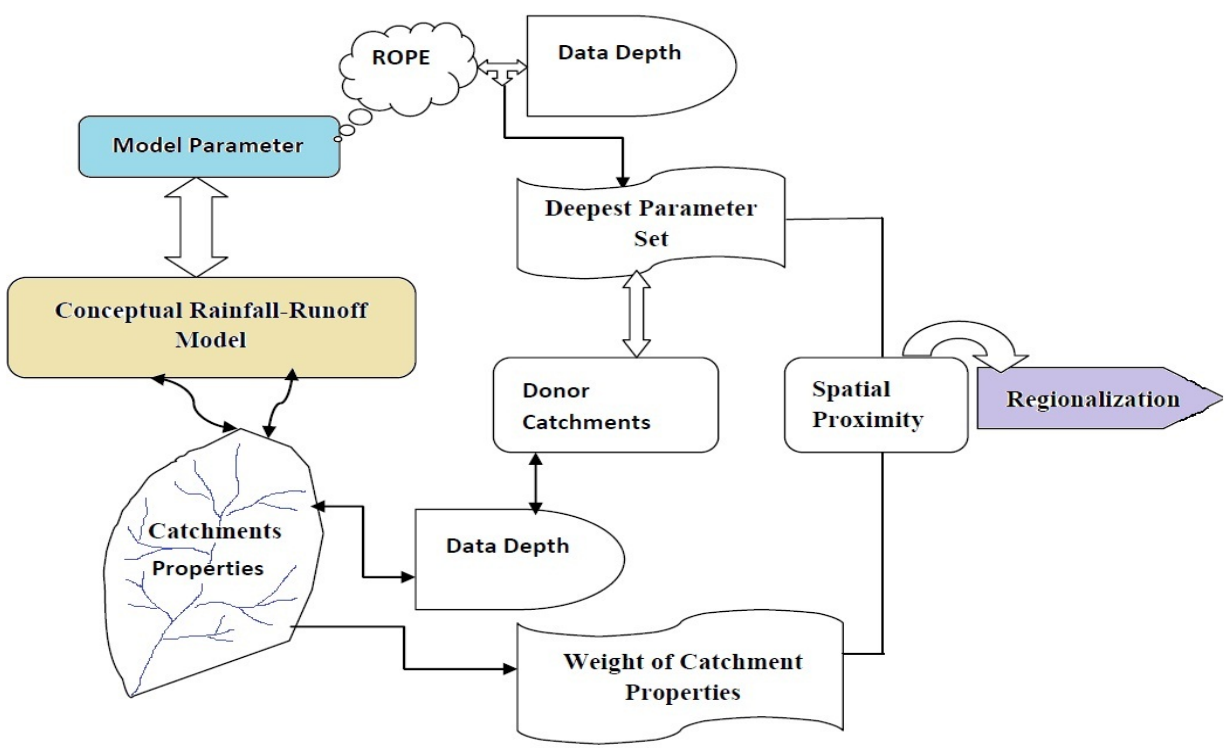

Fig. 4 Schematic diagram of newly developed RDS method for regionalization.

(spatial proximity) together gets this name RDS. ROPE algorithm [21] ensures all parameter vectors robust with hydrologically representative, insensitive as well as transferable with good model performance. Data depth function is used to find the boundary or the outlier of the catchments to identify donor catchments. Spatial proximity-transferring parameters from neighboring catchments to the ungauged catchment, considering climate and catchment conditions vary uniformly in space. Three key (ROPE-data depth-spatial proximity) concepts blend together to reach the goal. Regionalization focusing on relating compatible parameter sets or vectors to catchment properties is one of the key aspects in predicting ungauged basins. Step wise description of the RDS method is given below:

- Step 1: determination of donor catchments using data depth function with the help of catchment properties;

- Step 2: selection of conceptual rainfall-runoff 
model and outline the model parameters;

- Step 3: calibration with ROPE algorithm;

- Step 4: find the deepest parameter set of the donor catchments with data depth function;

- Step 5: develop the transfer function with catchment properties of donor catchments and ungauged catchments to find the model parameters of ungauged catchments. In this method, the authors define the function as min-max optimization. In this step, weights of the ungauged catchments will be found from the catchments properties of donor and ungauged catchments;

- Step 6: deepest parameter set of the donor catchments will determine the model parameters of the ungauged catchments from the weights of Step 5.

\subsection{Model Structures}

HYMOD is a conceptual rainfall-runoff model based on the probability-distributed principle of Moore [22]. Fig. 5 represents the overall structure of the model. This model performs firstly by characterizing the runoff production process at a point within the basin. Secondly, probability distributions describing the spatial variation of process parameters over the basin are used to derive algebraic expressions for the integrated flow response from the basin. In this study, modified HYMOD model [23] was used. The major modification was the addition of snow routing. The snow routine represents snow accumulation and melt by a simple degree-day concept, involving the DD (degree-day) factor and Th (threshold) temperature for snow melt initiation.

The main structure of the model contains a relatively simple rainfall excess model, connected with two series of linear reservoirs (three identical quick and a single for the slow response). It requires the optimization of eight parameters to observed stream flow data: the maximum storage capacity in the catchment, the degree of spatial variability of the soil moisture capacity within the catchment, the factor distributing the flow between the two series of reservoirs, and the residence time of the linear quick and slow reservoirs. The soil moisture routine represents runoff generation and changes in the soil moisture state of the catchment and involve three parameters: the maximum soil moisture storage $C_{\max }$, a parameter in the nonlinear function relating runoff generation to the soil moisture state, termed the nonlinearity parameter $\beta$ (Beta). Fig. 5 shows the systematic representation of the HYMOD. For more details about the model can be seen by the earlier studies of Wagener and Wheater [2] and Bárdossy and Singh [17].

Parameter range used for the simulation of the HYMOD model is given in Table 1.

\subsection{HBV Rainfall-Runoff Model}

The HBV model [24] is a conceptual rainfall-runoff model which simulates daily discharge, using input variables, i.e., daily rainfall, temperature and daily or

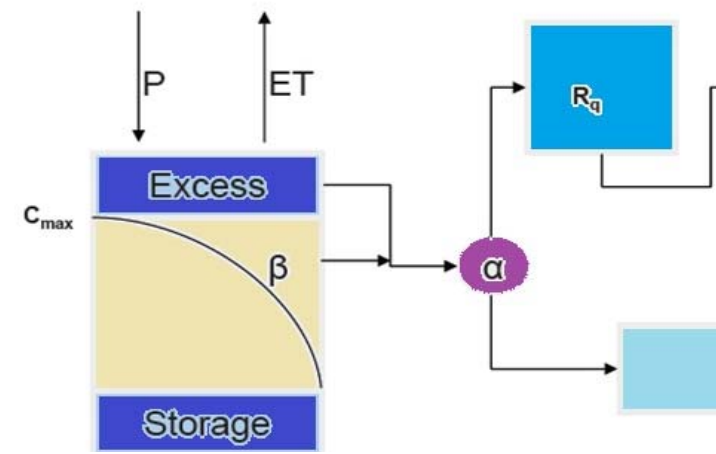

Soil moisture accounting
Routing

Fig. 5 Representation of conceptual hydrological model: HYMOD. 
Table 1 Model parameters range for the HYMOD.

\begin{tabular}{llll}
\hline Parameters & Description & Max & Min \\
\hline$C_{\max }$ & Maximum soil moisture storage & 600 & 150 \\
Beta & Degree of spatial variability of the soil moisture capacity & 8 & 3 \\
DD & Degree-day factor & 3 & 1 \\
Dew & Precipitation/ degree-day relation & 2 & 0 \\
Th & Threshold temperature for snow melt initiation & 1.500 & -1.000 \\
Alpha & Flow distributing factor & 0.8 & 0.2 \\
$R_{S}$ & Residence times of the slow reservoirs & 0.200 & 0.010 \\
$R q$ & Residence times of the quick reservoirs & 0.7 & 0.3 \\
\hline
\end{tabular}

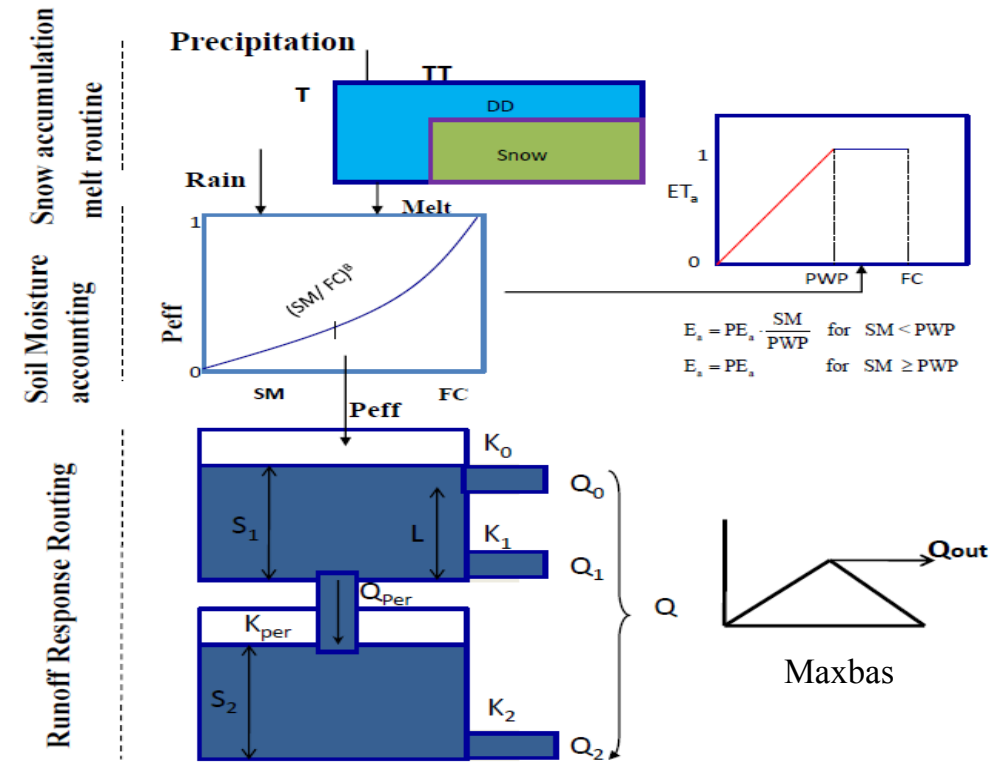

Fig. 6 Scheme of HBV rainfall-runoff model.

Table 2 Model parameters range for the HBV.

\begin{tabular}{llll}
\hline Parameters & Description & Max & Min \\
\hline$D D$ & Degree-day factor & 5 & 0.5 \\
Dew & Precipitation/degree-day relation & 2 & 0 \\
$T_{\text {crit }}$ & Threshold temperature for snow melt initiation & 2 & -2 \\
$\beta$ & Model parameter (shape coefficient) & 6 & 1 \\
$L$ & Threshold water level for near surface flow & 30 & 1 \\
$k_{0}$ & Near surface flow storage constant & 20 & 0.5 \\
$k_{1}$ & Interflow storage constant & 50 & 5 \\
$K_{\text {perc }}$ & Percolation storage constant & 100 & 20 \\
$k_{2}$ & Base flow storage constant & 1,000 & 10 \\
\hline
\end{tabular}

monthly estimates of ETO (evapo-transpiration). A number of studies have recognized its suitability in regionalization studies $[10,14,15,25]$. Systematic representation of the HBV Model is given in Fig. 6. The HBV model consists of different routines representing the snow accumulation and snowmelt by a degree-day method, recharge and actual evapo-transpiration as functions of the actual water storage in a soil box, runoff generation by two linear reservoirs with three possible outlets (i.e., runoff components), and channel routing by a simple triangular weighting function. Parameter range used for the simulation of the HBV model is given in Table 2 . 


\subsection{Min-Max Optimization}

Generally, it is assumed that the physical and climatic characteristics are relatively homogeneous within a region, to ensure neighbors behave similarly. As a part of RDS method, the spatial proximity approach is used which consists of transferring parameters from neighboring catchments to the ungauged catchment. In this section procedure of calculating the weight $\left(W_{i}\right)$ of the catchment properties from donor catchments will be elaborated. Tables 3 and 4 represent the catchment properties of donor and pseudo ungauged catchments.

$P_{1}, P_{2} \ldots P_{5}$ is defined as catchment properties and in the corresponding column, values of the five different properties are given as $X_{1}, Y_{1} \ldots V_{l}$. As for example $P_{l}$ is a property of the catchments called FC (field capacity), so $X_{1}$ is a $\mathrm{FC}$ value for catchment $1, X_{2}$ is another value of Field capacity but from catchment 2. Similarly, Table 4 represents the catchment properties of the ungauged basins. To find the optimized weight, formulation of the equation system and optimization criteria is needed. The process of this optimization can be called as min-max optimization.

Min-max optimization:

Step 1:

The equation system for the optimization will be (as per Tables 3 and 4)

$$
\begin{aligned}
X_{U 1}= & \sum X_{i} W_{i} \\
Y_{U 1}= & \sum Y_{i} W_{i} \\
& \cdots \\
V_{U 1}= & \sum V_{i} W_{i}
\end{aligned}
$$

$i=1$ to $n$

Step 2:

Criteria for the optimization are:

$$
\begin{aligned}
& W_{i} \geq 0 ; \mathrm{i}=1 \text { to } n \\
& \sum W_{i}=1 ; \mathrm{i}=1 \text { to } n
\end{aligned}
$$

Step 3:

Finally to smoothen the distribution of the weight, optimization is done with the algorithm minimum $\left(\operatorname{Max}\left(W_{i}\right)\right)$. "Equal" weighting of the donors is ensured
Table 3 Donor catchments with five different properties.

\begin{tabular}{llllll}
\hline Donor catchments & \multicolumn{5}{c}{ Properties } \\
\hline ID & $P_{1}$ & $P_{2}$ & $P_{3}$ & $P_{4}$ & $P_{5}$ \\
1 & $X_{1}$ & $Y_{1}$ & $Z_{1}$ & $U_{1}$ & $V_{1}$ \\
2 & $X_{2}$ & $Y_{2}$ & $Z_{2}$ & $U_{2}$ & $V_{2}$ \\
3 & $X_{3}$ & $Y_{3}$ & $Z_{3}$ & $U_{3}$ & $V_{3}$ \\
$:$ & $:$ & $:$ & $:$ & $:$ & $:$ \\
$:$ & $:$ & $:$ & $:$ & $:$ & $:$ \\
$:$ & $:$ & $:$ & $:$ & $:$ & $:$ \\
$\mathrm{n}$ & $X_{n}$ & $Y_{n}$ & $Z_{n}$ & $U_{n}$ & $V_{n}$ \\
\hline
\end{tabular}

Table 4 Ungauged catchments with five different properties.

\begin{tabular}{lllccc}
\hline Ungauged catchments & \multicolumn{5}{c}{ Properties } \\
\hline ID & $P_{1}$ & $P_{2}$ & $P_{3}$ & $P_{4}$ & $P_{5}$ \\
U1 & $X$ & $Y$ & $Z$ & $U$ & $V$ \\
\hline
\end{tabular}

with the use of unique weight through this min-max optimization.

\section{Results}

\subsection{Predicting Ungauged Basins-A New Paradigm}

Uncertainty, ungauged and understanding (physical process $)-3 \mathrm{U}$ is the vital part of Hydrology. To give a breakthrough in PUB (predicting ungauged basins) is not an easy task. There is a whole spectrum of cases, which can be collectively embraced by the term "ungauged basins". There are different grades of being "ungauged". Some basins are genuinely ungauged, others are poorly gauged. In some basins, which had previously been gauged, monitoring may have discontinued. But even in gauged catchments, gauges may be overtopped and destroyed by a high flood and the maximum flood levels need to be sought indirectly, e.g., via tracking the maximum water level on walls. If gauges survive and continue operating, there is still no reliable rating curve for determination of extreme floods. In this range, flows are notoriously ungauged [11]. Hydrological data are also indispensable for enhancing understanding of variables characterizing hydrological processes (fluxes) and the states (storages) of hydrological systems (drainage basins). With the consideration of uncertainty, the authors make a drive to develop a methodology to predict ungauged basins. 
Newly developed RDS method shows high optimism in predicting the ungauged basins.

\subsubsection{Prediction with HYMOD in RDS Method}

Application of RDS method shows significant success in HYMOD. Analysis shows more than 90\% success rating in predicting the ungauged basins. Approximately, $10 \%$ failure is justifiable with solid reasons. To explain the extent of the accuracy of the outcome, output of the model is divided in three parts: Part-1: Regionalized with less than $20 \%$ deviation with the model; Part-2: Regionalized with less than 50\% deviation (excluding the part-1); Part-3: Complete failure with more than $50 \%$ deviation. Out of 74 ungauged basins 52 catchments show very close result with the model result with less than $20 \%$ divergence. Fourteen more catchments resemble with the model result by less than $50 \%$ deviation. Only eight catchments do not respond with HYMOD in RDS method accordingly. Fig. 7 shows HYMOD model performance and regionalized performance through applied RDS method to predict ungauged basins.

\subsubsection{Prediction with HBV in RDS Method}

Regionalization by RDS method using HBV model brings high optimism to predict ungauged basins. The authors' analysis shows more than $95 \%$ success in predicting ungauged basins. Approximately $5 \%$ failure is permissible considering the human induced effect. Fig. 8 shows HBV model performance and the applied RDS method regionalized performance to predict ungauged basins. Out of 74 ungauged basins 45 catchments show very close result with the model result with less than $20 \%$ divergence. Twenty five more catchments resemble with the model result by less than $50 \%$ deviation. Considering this fact only four catchments that do not respond with $\mathrm{HBV}$ in RDS method accordingly. In summary, regionalization through RDS method with HBV model shows remarkable performance.

4.1.3 Comparison between HYMOD and HBV in Predicting Ungauged Basins

Model performance NS (Nash-Sutcliffe) model efficiencies of donorcatchments and pseudo (assumed)

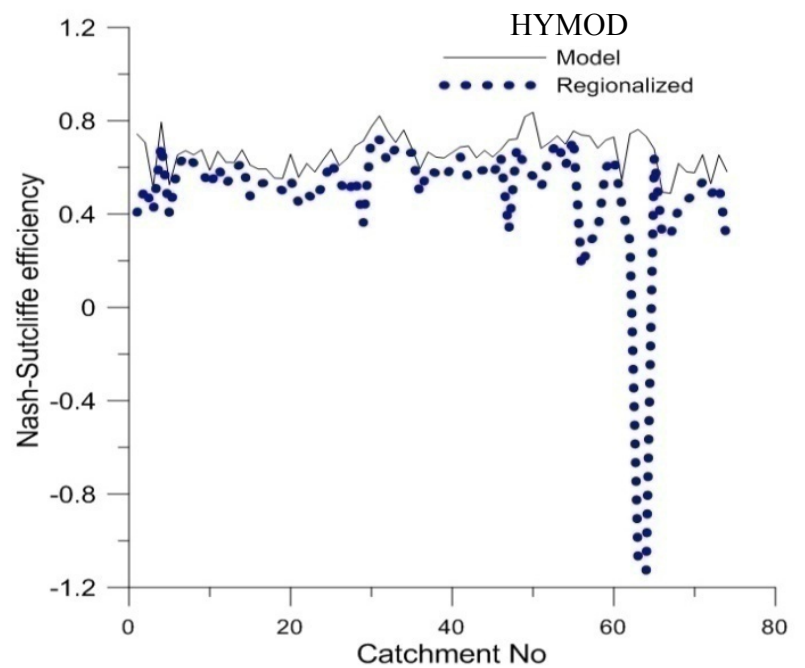

Fig. 7 Comparison of Nash-Sutcliffe model efficiencies with the regionalized value to PUB with HYMOD.

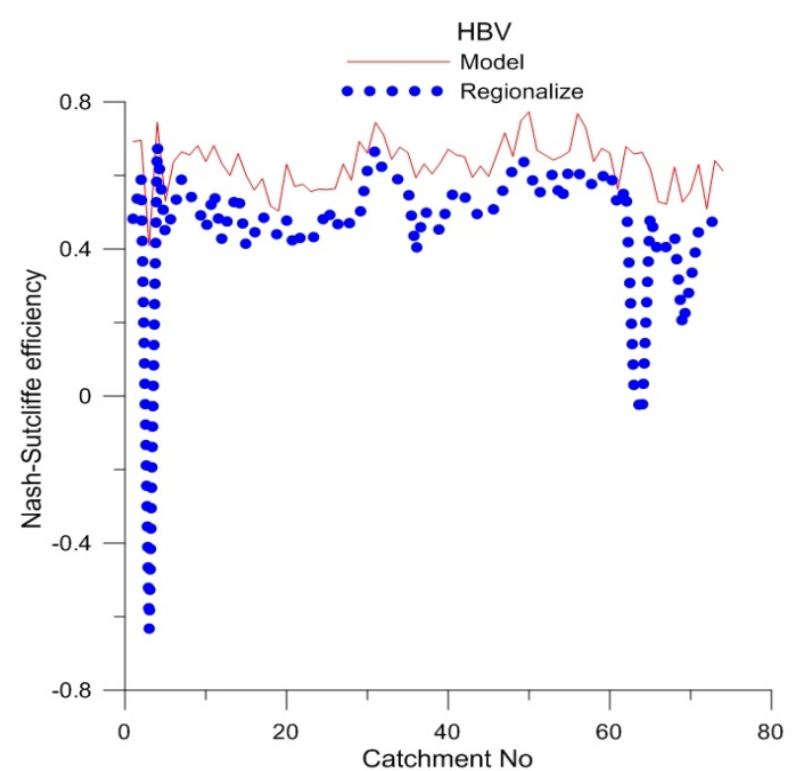

Fig. 8 Comparison of Nash-Sutcliffe model efficiencies with the regionalized value to PUB with $\mathrm{HBV}$.

ungauged catchments are shown in Fig. 9. In most of the cases model performance in HYMOD is a bit higher than HBV. Uncertainty with increasing number of parameter could be a reason of lower performance in HBV. The complete scenario of the effectiveness of RDS method is shown in Fig. 9. It is undoubtedly perceptible that newly developed RDS method is very effective in predicting ungauged basin and regionalization is independent of the conceptual rainfall-runoff model. Out of 74 pseudo ungauged catchments, four regionalization unsuccessfulness in 
HBV model, eight in HYMOD signifies the robustness of the method. Two catchments unsuccessfulness occurred in both HYMOD and HBV. Figs. 10-12 show the hydrograph of the three different regionalized catchments. From the flow duration curve, it is clearly seen that the regionalized flow almost capture the whole scenario of the pseudo ungauged catchments.

\subsection{RDS Method Comparison in Different Parameter} Sets

The effectiveness of the different parameter sets has been analyzed, by considering the deepest, mean and maximum parameter set to find out the suitability in predicting ungauged basins. Fig. 13 shows the comparison of the model efficiency with the regionalized

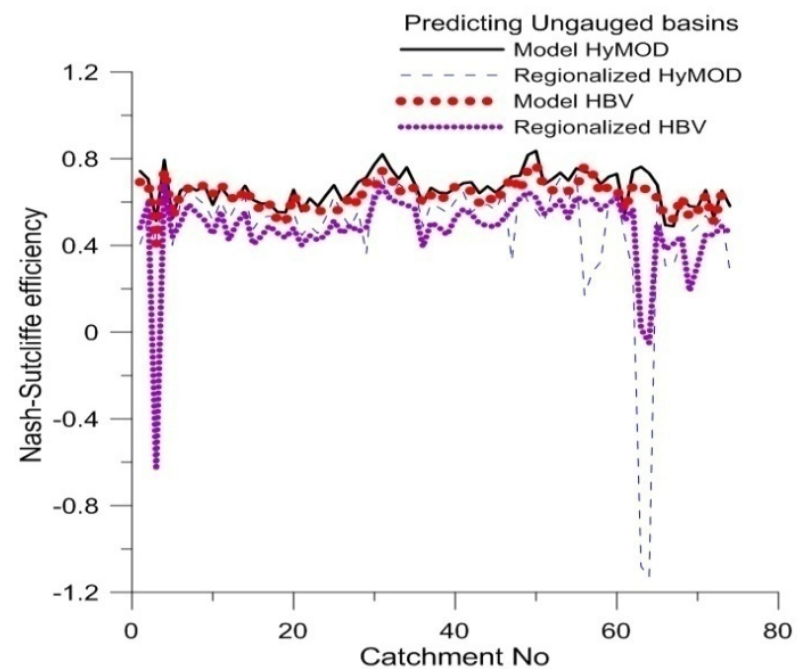

Fig. 9 Comparison of Nash-Sutcliffe model efficiencies with regionalized efficiency of the ungauged catchments through HYMOD and HBV.
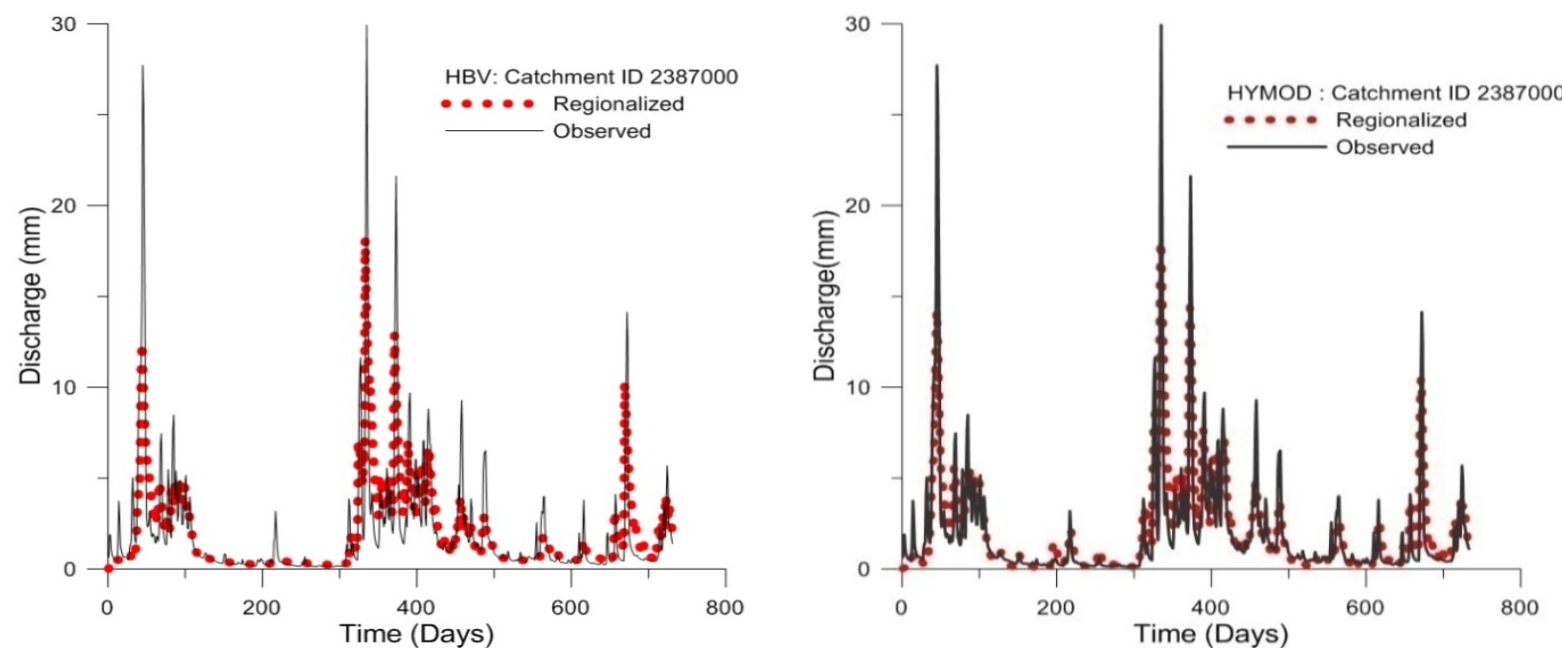

Fig. 10 Hydrograph comparing regionalized data with observed data in HYMOD and HBV for pseudo ungauged catchment (ID: 2387000) at Eastern USA.
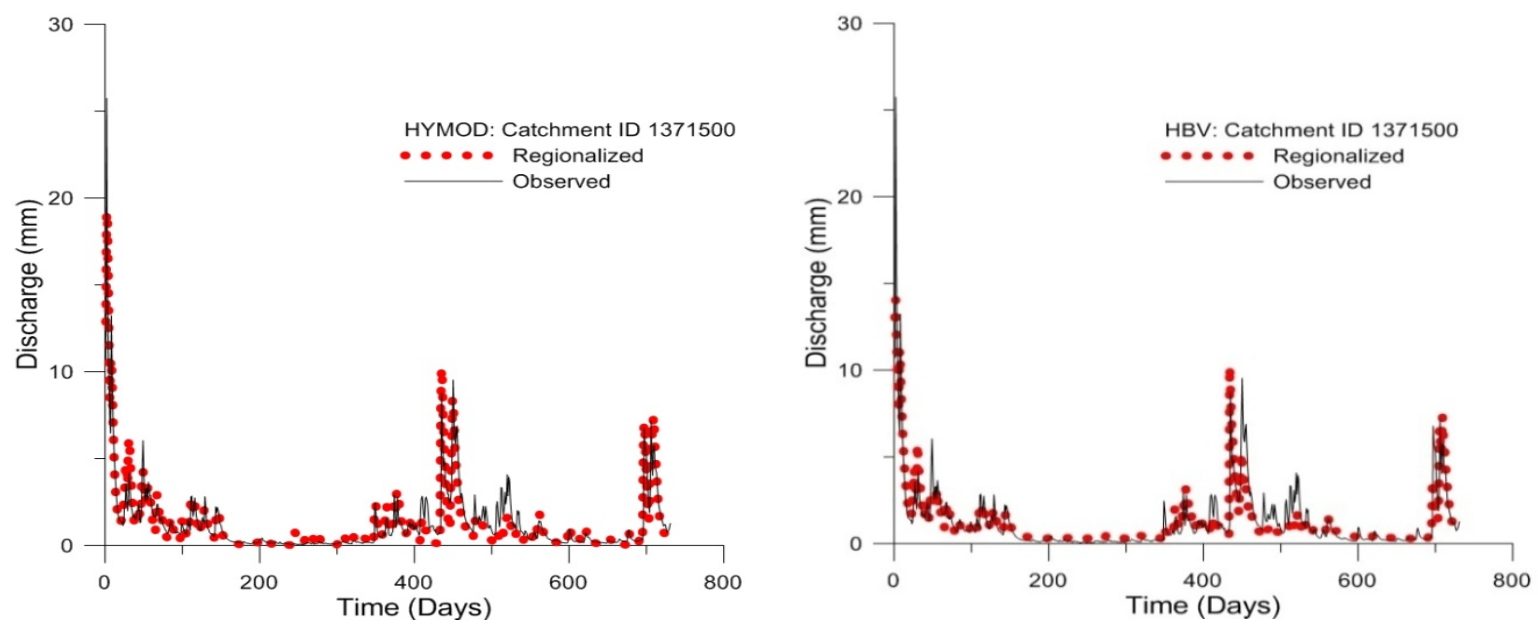

Fig. 11 Hydrograph comparing regionalized data with observed data in HYMOD and HBV for pseudo ungauged catchment (ID: 1371500) at Eastern USA. 

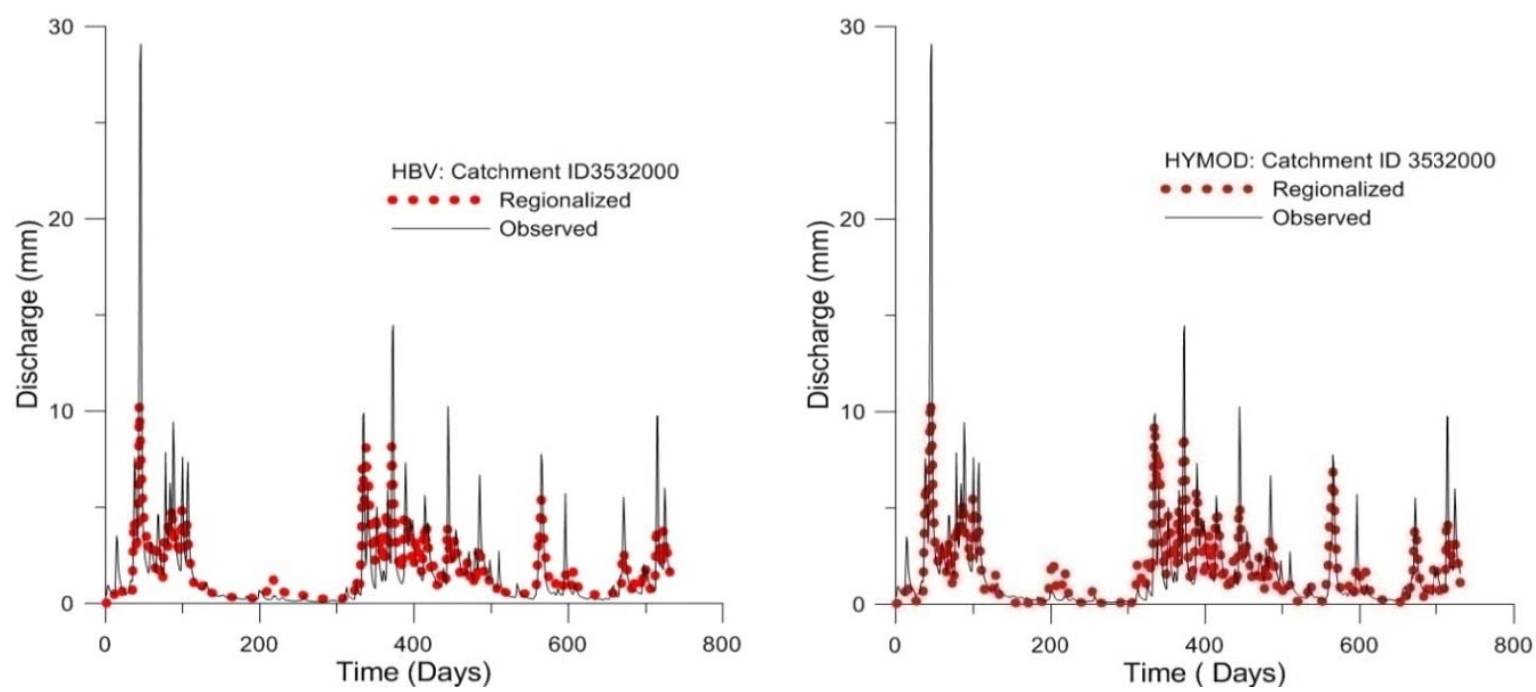

Fig. 12 Hydrograph comparing regionalized data with observed data in HYMOD and HBV for pseudo ungauged catchment (ID: 3532000) at Eastern USA.

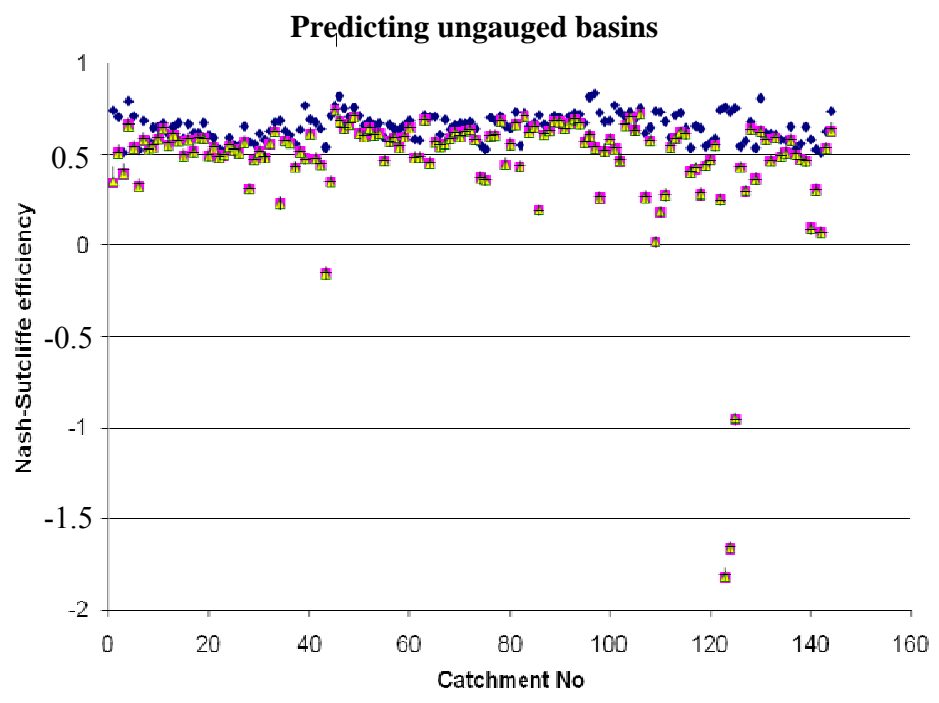

$\bullet$ Model NS

- Regio_Deepest Parameter

$\triangle$ Regio_Mean Parameter

+Regio_Max NS parameter

Fig. 13 Comparison of Nash-Sutcliffe model efficiencies with regionalized efficiency considering three different parameter sets to predict the ungauged catchments through HYMOD.

model efficiency considering deepest, mean and maximum parameter set. It shows almost identical results in predicting ungauged basin considering all three cases, though a little improvement is visible while considering parameter sets with maximum NS.

\subsection{Regionalization of Model Parameters Based on} Catchment Similarity in Predicting Ungauged Basins

FDCs (flow duration curves) similarity analysis: similarity in the FDCs was compared both by means of visual inspection and by using a commonly used objective criterion based on the RRMSE (relative root mean square error). FDCs are very good indicator in comparing the hydrological response of catchments [14].

$$
\text { RRMSE }=\frac{\sqrt{\frac{1 \sum_{i=1}^{N}\left(Q_{i}-\hat{Q}_{i}\right)^{2}}{N}}}{\overline{Q_{i}}}
$$

where, $Q_{i}$ is the i-th flow percentile $(\mathrm{mm} / \mathrm{d})$ of one FDC and $i$ ranges from 1 to $N, \hat{Q}_{i}$ is the corresponding $\mathrm{i}$-th 
flow percentile $(\mathrm{mm} / \mathrm{d})$ of another FDC, and $\bar{Q}_{i}$ is the mean discharge of the first baseline FDC. The RRMSE values were calculated for the whole FDC corresponding to the flow percentiles $Q_{0}$ to $Q_{100}$ using daily discharge data. The authors analyzed the FDC curves as per climatic condition. Figs. 14-16 show the RRMSE of the wet, medium and dry catchments. It clearly shows the unsuccessfulness in regionalization process to predict ungauged basins.

4.4 Regionalization with the Spatial Proximity Approach

Catchments that are close to each other have been assumed similar behavior, since climate and catchment conditions usually vary evenly in space.
The spatial proximity approach consists of transferring parameters from neighboring catchments to the ungauged catchment. This approach is instinctively attractive, even though it depends on the density of the gauged basin network. In this paper, it has been considered that the parameter averaging options to combine the information from donor catchments. A regional set of parameters is computed as the mean of parameters from donor gauged catchments and applied to the ungauged catchment. Donor catchments were selected considering the proximity of the ungauged catchments to the gauged ones. Figs. 17a and 17b represent the catchments that were considered to check the applicability of the spatial proximity approach.

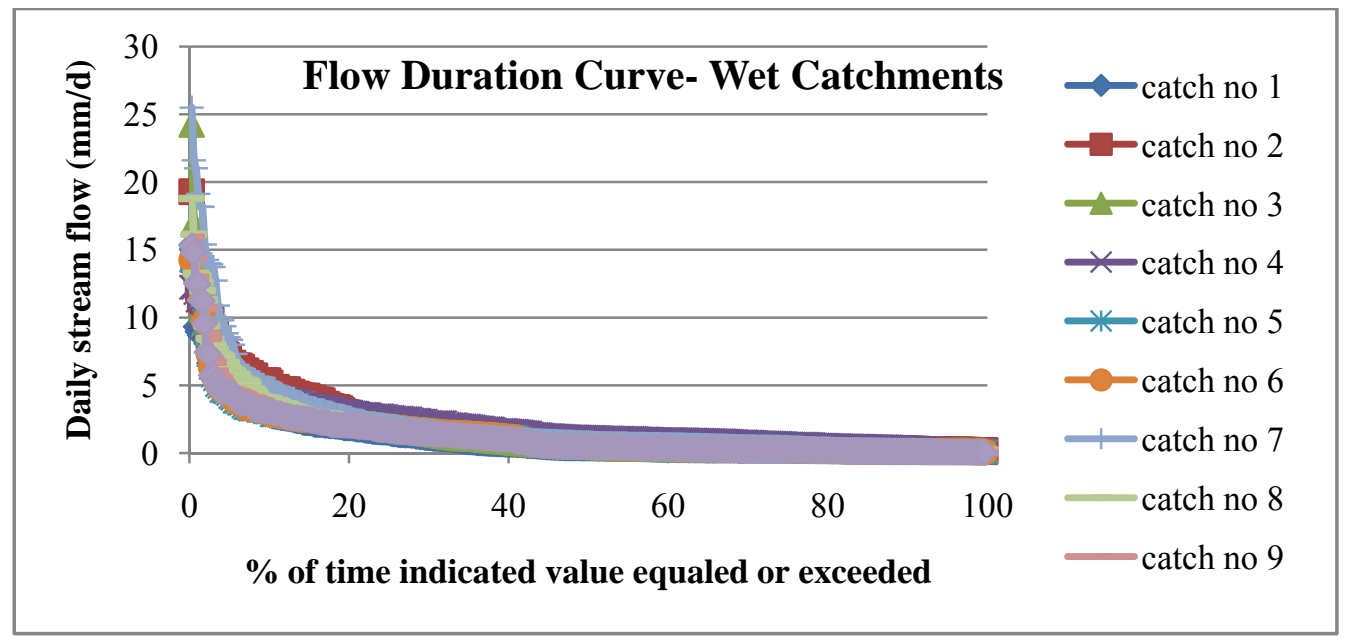

Fig. 14 Comparison of flow duration curve for wet catchments in the similarity analysis.

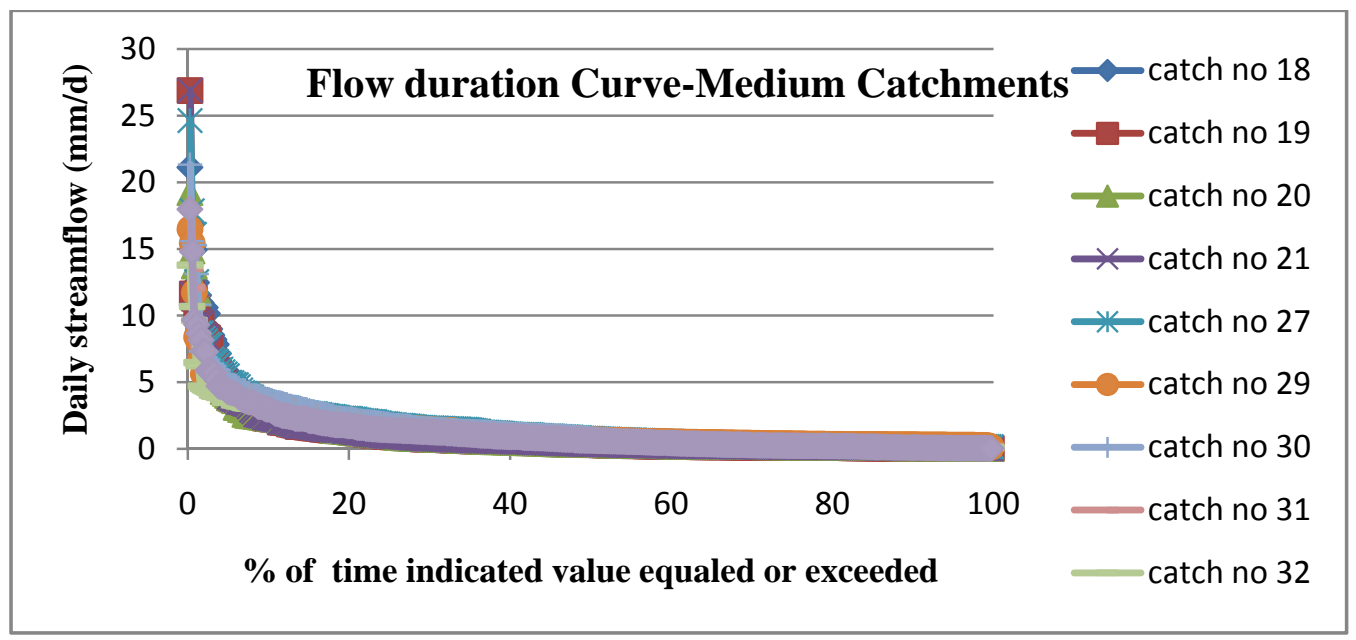

Fig. 15 Comparison of flow duration curve for medium catchments in the similarity analysis. 

Approach Based on Eastern USA Catchments

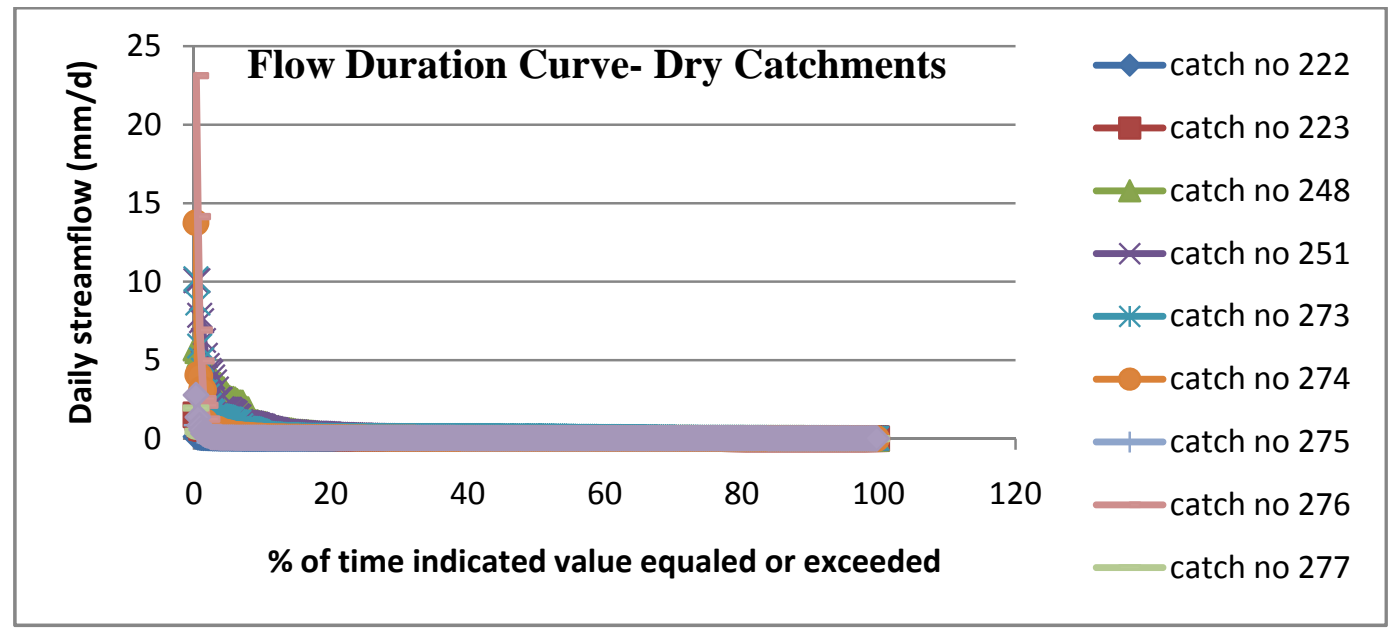

Fig. 16 Comparison of flow duration curve for dry catchments in the similarity analysis.
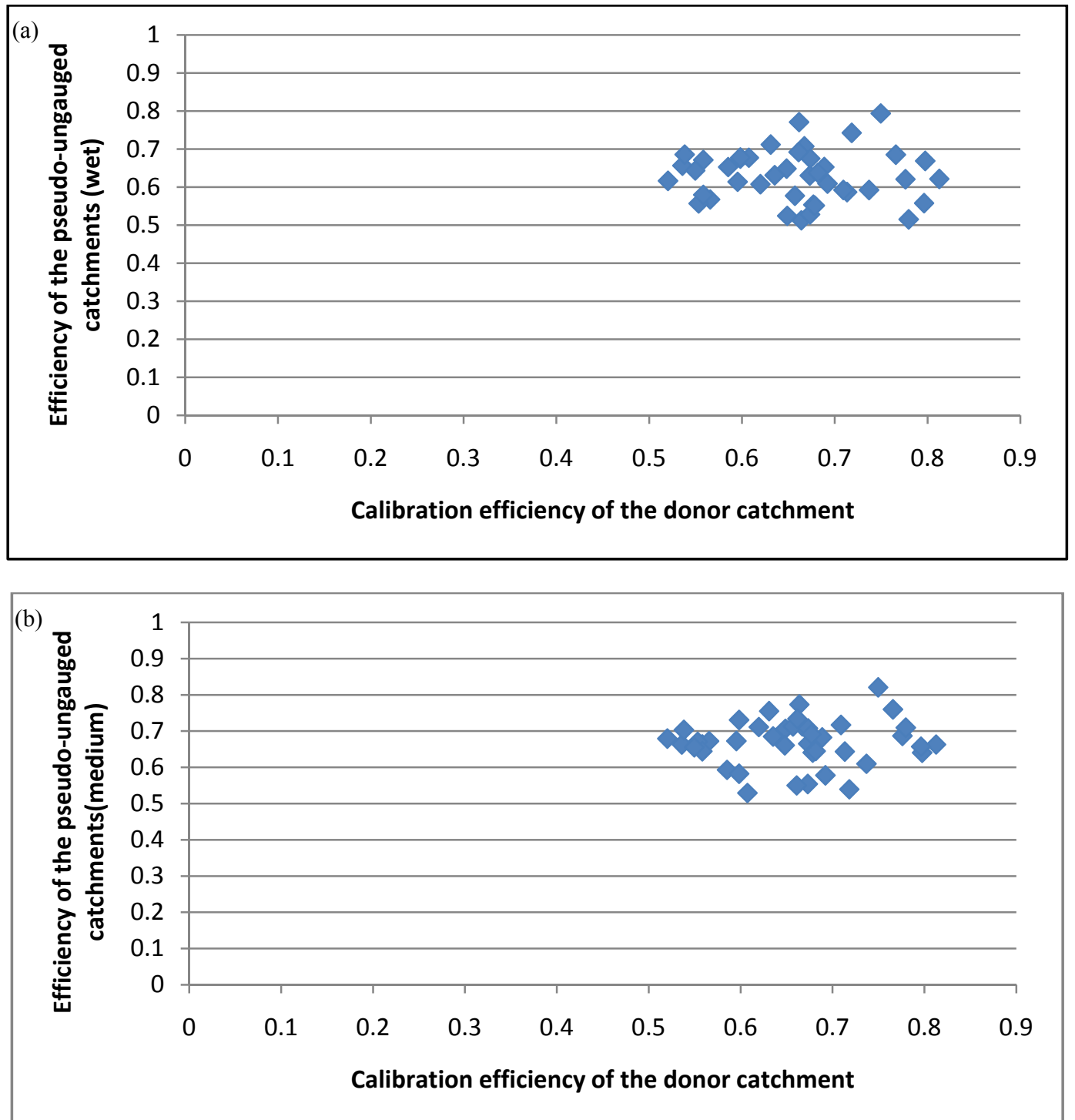

Fig. 17 Relationship between the calibration efficiency of the HYMOD model for donor gauged catchments and efficiency of the model on pseudo-ungauged catchments: (a) wet catchments; (b) medium catchments. 


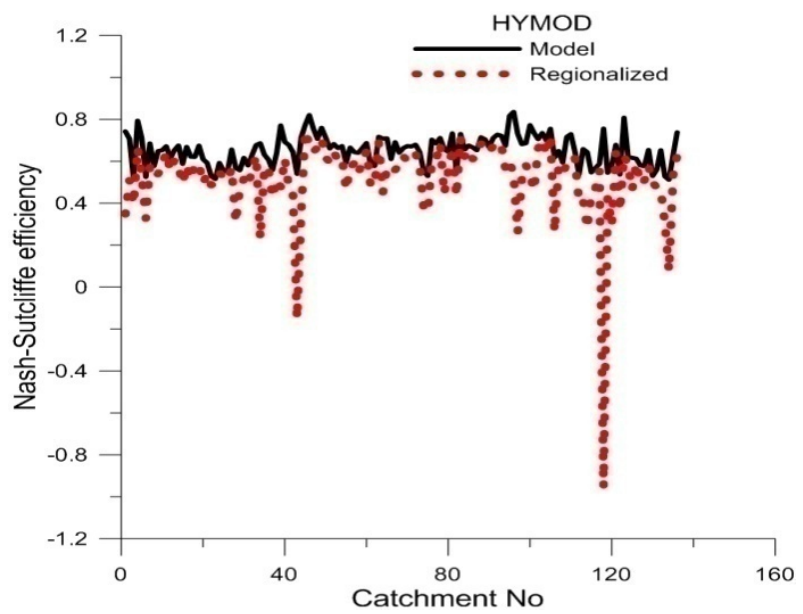

Fig. 18 Comparison of Nash-Sutcliffe model efficiencies with the regionalized value to PUB with HYMOD universality of RDS method.

\subsection{Universality of RDS Method: Expansion of the} Study Domain

The possibility of predicting more ungauged basin within the concept of RDS method has been discussed with justification. Out of 279 catchments of the Eastern USA, calibration of the 241 catchments is reasonably good. Using data depth function, the authors selected 42 catchments as donor catchments with depth equal to zero. Higher depth value between donor catchments and remaining 199 catchments were sorted to assume the catchments as ungauged. About 144 catchments are assumed as ungauged catchments. HYMOD was used as the conceptual rainfall-runoff model. The application of the RDS method shows again near about $90 \%$ success in predicting ungauged basins. Fig. 18 shows the regionalized NS-efficiency with the model NS-efficiency in the 136 ungauged basins.

\section{Conclusions and Discussions}

Climate unevenness, flood and drought risk, erosion and sediment transport, and their impacts on water resources and water quality management enhanced the significance of PUB (predicting ungauged basins). On the way to PUB, considering all the aspects, RDS method shows the robustness and effectiveness in predicting the ungauged information. Regionalization by RDS method using HBV model brings high optimism to predict ungauged basins. Analysis shows more than $95 \%$ success with $\mathrm{HBV}$ in predicting ungauged basins. Approximately, 5\% failure is permissible considering the human induced effect. Application of RDS method shows significant success in HYMOD. Analysis shows more than 90\% success with HYMOD in predicting ungauged basins. Approximately, $10 \%$ failure is justifiable considering diversity of the catchment properties. It is possible to conclude that regionalization is independent of the conceptual rainfall-runoff model. Increase or decrease of catchment properties is unable to show any significant influence in the model performance of the regionalization process. One of the most advantages of the RDS method is once the weighting function (min-max optimization) of the catchment properties is calculated, it gives liberty to use any conceptual rainfall-runoff model as per requirement. Uses of two different rainfall-runoff models provide general insights on the regionalization issue. The use of the different regionalization approaches in this study in a harmonizing fashion, i.e., in a multi-regionalization approach, could be another reason to the effectiveness of the RDS method.

Many endeavors have been made to decide which regionalization approach was the most appropriate, but the results were not lucid since many of these studies were based on relatively small catchment data sets. To overcome the drawback, this paper analyzed large data set of Eastern USA catchments and a different light in methodological development to predict ungauged basins is visible with the performance of the method. It is highly expected that the methodology presented in this paper is easy to imitate in other catchments of the earth.

\section{References}

[1] A. Bárdossy, Calibration of hydrological model parameters for ungauged catchments, Hydrol. Earth System Science 11 (2007) 703-710. 
[2] T. Wagener, H.S. Wheater, Parameter estimation and regionalization for continuous rainfall-runoff models including uncertainty, J. Hydrol. 320 (2006) 132-154.

[3] V. Klemes, Dilettantism in hydrology: Transition or destiny?, Water Resour. Res. 22 (9) (1986) 177-188.

[4] G. Blöschl, A. Montanari, Climate change impacts-Throwing the dice?, Hydrol. Processes 24 (2010) 374-381.

[5] Y. Hundecha, A. Bárdossy, Modeling of the effect of land use changes on the runoff generation of a river basin through parameter regionalization of a watershed model, Journal of Hydrology 292 (2004) 281-295.

[6] M. Sivapalan, K. Takeuchi, S.W. Franks, V.K. Gupta, H. Karambiri, V. Laxmi, et al., IAHS decade on predictions in ungauged basins (PUB), 2003-2012: Shaping an exciting future for the hydrological sciences, Hydrolog. Sci. J. 48 (6) (2003) 857-880.

[7] T. Wagener, M. Sivapalan, P.A. Troch, R.A. Woods, Catchment classification and hydrologic similarity, Geog. Comp. 1 (4) (2007) 901-931.

[8] M. Yadav, T. Wagener, H. Gupta, Regionalization of constraints on the expected watershed response behavior for improved predictions in ungauged basins, Adv. Water Resour. 30 (2007) 1756-1774.

[9] W.L. Magette, V.O. Shanholtz, J.C. Carr, Estimating selected parameters for the Kentucky watershed model from watershed characteristics, Water Resour. Res. 1 (1976) 472-476.

[10] R. Merz, G. Blöschl, Regionalisation of catchment model parameters, J. Hydrol. 287 (2004) 95-123.

[11] Z.W. Kundzewicz, Prediction in ungauged basins-A systemic perspective, IAHS Publ. 309 (2007) 38-44.

[12] R.J. Nathan, T.A. McMahon, Identification of homogeneous regions for the purpose of regionalization, J. Hydrol. 121 (1990) 217-238.

[13] A. Castellarin, G. Galeati, L. Brandimarte, A. Montanari, A. Brath, Regional flow-duration curves: Reliability for ungauged basins, Adv. Water Resour. 27 (2004) 953-965.

[14] I. Masih, S. Uhlenbrook, S. Maskey, M.D. Ahmad, Regionalization of a conceptual rainfall-runoff model based on similarity of the flow duration curve: A case study from the semi-arid Karkheh basin, Iran, Journal of Hydrology 391 (2010) 188-201.

[15] J. Götzinger, A. Bárdossy, Comparison of four regionalisation methods for a distributed hydrological model, Journal of Hydrology 333 (2006) 374-384.

[16] I. Masih, S. Uhlenbrook, S. Maskey, M.D. Ahmad, Regionalization of a conceptual rainfall-runoff model based on similarity of the flow duration curve: A case study from the semi-arid Karkheh Basin, Iran, Journal of Hydrology 391 (2010) 188-201.

[17] A. Bárdossy, S.K. Singh, Regionalization of hydrological model parameters using data depth, Hydrology Research 4 (5) (2011) 356-371.

[18] M. Goswami, K.M. O'Connor, K.P. Bhattarai, Development of regionalization procedures using a multi-model approach for flow simulation in an ungauged catchment, J. Hydrol. 333 (2007) 517-531.

[19] S.A. Shoaib, R. Baur, N. Sultana, M.A. Haque, M.J. Hossain, Sustaining the in stream flow of rivers: Comparative case study of Germany and Bangladesh, Asian Journal of Water, Environment and Pollution 8 (1) (2011) 1-7.

[20] M.I. Budyko, Climate and Life, Academic Press, New York, 1974.

[21] A. Bárdossy, S.K. Singh, Robust estimation of hydrological model parameters, Hydrology and Earth System Science 12 (2008) 1273-1283.

[22] R.J. Moore, The probability-distributed principle and runoff production at point and basin scale, Hydrological Sciences Journal 30 (2) (1985) 273-297.

[23] S.K. Singh, Robust parameter estimation in gauged and ungauged basins, Ph.D. Thesis, University of Stuttgart, 2010.

[24] S. Bergström, The HBV Model in Computer Models of Watershed Hydrology, in: V.P. Singh (Ed.), Water Resour. Publ., Highlands Ranch, Colo, 1992, pp. 443-476.

[25] J. Seibert, Regionalization of parameters for a conceptual rainfall-runoff model, Agric. Forest Meteor. 98 (99) (1999) 279-293. 